charging" ... "We are currently looking at resource allocation models which may well include networking costs".

Imperfections apart, the survey has revealed diverse patterns of service provision and fiscal responsibility in the three different groups (1992, 1961-1992, pre-1961). It may be that networking in the "university sector" cannot be explored with one instrument. Just as the world of management is often researched in separate categories of small, medium and large enterprises, separate probes may be required to explore accounting practice and networking in Groups A, B and C.

\title{
References
}

1. Follett, B (chair). The Joint Funding Councils Libraries' Review Group Report (the Follett Report). London: HEFCE, SHEFC, HEFCW, DENI, 1993.

2. Royal Society. The STM information system in the UK. London: the Royal Society, the British Library and the Association of Learned and Professional Society Publishers, 1993.

3. East, $\mathrm{H}$ and Tilson, $\mathrm{Y}$. The liberated end-user. Developments in practice and theory for database provision to the academic community. London: British Library, 1993.

4. Scanlon, S. BIDS: the revolution in database access. Serials, 5 (1), 1992, p18-28. The World of Learning, 44th edition 1994. London: Europa Publications Ltd, 1993.

5. The World of Learning, 1994. 44th edition, London: Europa Publications ltd, 1993.

6. Sumsion, J. Survey of resources and uses in higher education libraries, UK 1993. Loughborough: Loughborough University of Technology Library and Information Statistics Unit, 1994.

7. Baker, D. Resource allocation in university libraries. Journal of Documentation, 48 (10), 1992 p1-19.

\section{Quality assurance at St Francis Xavier Sixth Form College Library}

\author{
KRISTA ROBERTS \\ Thames Valley University
}

The following article is based on Krista's work which was awarded the TC Farries/LIRG Undergraduate Prize.

\section{Introduction}

This article outlines the work undertaken between September 1992 and May 1993 when I carried out the research to set up a full Quality Assurance programme to be implemented within St Francis Xavier College (SFX) Library. Guidelines for a college-wide programme were being drawn up as I began and it was expected that my work would fit in with these. This article describes the background to the work, an analysis of the key issues of quality assurance, and a description of our resultant methodology. In conclusion the article makes recommendations on how to develop 
a QA programme in a sixth form library environment.

In 1992 SFX Library catered for 800 students. It had a stock of 14,000 books/AV materials, subscribed to 50 periodicals and held 4 computers and $1 \mathrm{CD}$-ROM for student use. The library was staffed by a full-time librarian, a part-time librarian (term-times only) and a full time administrative assistant (term-times only). Opening hours were $8.30 \mathrm{am}$ to $4.30 \mathrm{pm}$, Monday to Friday.

\section{Changes in the $F E$ sector}

In April 1993 the FE/sixth form sector underwent a number of changes. Taken out of local government control, colleges are now funded directly by the Government through a new council (FEFC). With colleges receiving an element of their funding related to actual student numbers, the market has become increasingly competitive and, as a result, not only has a high standard of performance in all aspects of the college become necessary, but there must also be evidence of the quality of service. The FEFC has a responsibility for ensuring that quality systems form a satisfactory basis for the funding being provided.

\section{Key issues}

\section{What is Quality Assurance}

One of the major problems with any QA programme is to define the terminology, particularly within the services sector. Reading the literature it is easy to get confused about the number of terms used to define similar and related procedures. This is not the place for an in-depth discussion of terminology: suffice to say our approach was to apply easily comprehensible definitions.

As individual customer requirements of a service vary, so do expectations about the standard of service and finally the decision about whether the service provided fulfils their expectations satisfactorily. Assurance is easier to define; a guarantee, a promise. So QA could be defined as a promise to live up to customer expectations; a guarantee to provide a service specific to customer requirements. If quality is subjective, relative to individual user requirements and expectations, how feasible is it to seek to satisfy everyone? The route we took to achieving this task was to create an environment and management system dedicated both to identifying customer needs and to ensuring that a quality service is given, in which case the foundations are laid to keep that promise in the vast majority of cases.

\section{The benefits of $Q A$}

Why bother? In the case of many organizations at present the answer to this is external pressure. But aside from maintaining funding, what are the benefits? To imply that external pressure is the only reason to establish a QA scheme would be wrong; the more positive motivation should be a desire to improve the services within the library. The processes involved in QA; the setting of standards; the measuring to see whether these have been attained; the examination of the failings, analysis of the strengths; and review and re-evaluation of the standards should be an on-going cycle, a normal part of day-to-day management. The effect? To give the manager a more detailed knowledge of, and insight into, the strengths and weaknesses of the department. This will enable more realistic and effective planning, both in terms of short term objectives and strategic planning for the future. Factual data will ensure that the manager is in a position to justify funding, to defend his/her position or to aid public accountability. With a knowledge of the weaknesses of the 
department, problems can be foreseen and avoided. Decision-making will be facilitated and improved, the definition and evaluation of policy will be easier, and there should be a continual improvement in service levels.

\section{The problems}

Measuring quality. The first problem has been covered briefly in the definition of quality; as quality is subjective, differentiated according to individual user goals and requirements, how can it be measured?

Defining the aims. There are at least two aims in any QA programme; one is to justify resources, the other is to satisfy users. The former will largely measure inputs to the service, the latter will concentrate on the outputs. Which, if either, should take priority? There is no escaping the fact that quality is affected by available resources and if resources are not available, then quality will suffer.

Perpetuating mediocrity. Christine Oldham describes a further problem: "The starting point for such studies is the status quo. The assumption ... that the library or information service is providing a satisfactory service. The analysis, at worst, is an opportunity to collect data to support that assumption ${ }^{(1)}$. How can this be avoided? There is little point in perpetuating the mediocrity of the service.

Time and money. Setting up a QA system takes time. It could be argued that given limited resources, staff hours would be better spent in actually providing the service rather than setting up systems and increasing paperwork which distract library staff from the end user.

Data collection. It is vital that the collection of data does not detract from the day-to-day running of the department. However, it is equally important to collect sufficiently accurate data to reflect a true picture.

Staff commitment. Because it is natural that staff identify with their duties, any investigation into procedures could lead to hostility. The answer is the total involvement of all staff from the outset. Moreover, the contribution and input from staff can be invaluable.

\section{The methods}

Different methodologies have been discussed at length in the literature of the field, there is neither time nor space to analyze each individually in this article. Do remember, however, that there is no one definitive version, no " ... neat and easily applied management formula.." (1) because as client needs differ so do objectives and aims. Fredenburg's study includes a ten point checklist, on how to develop and establish a QA programme. Perhaps the most useful is "Realize that QA is an idea with many approaches. Adapt those that work for you and omit the ideas that don't apply. Also realize that QA is as individual as each library represented here, hence no instant QA guide and 'no canned' programs with answers for all libraries' questions ${ }^{(2)}$ ".

There are many equally valid methods of QA. From detailed examination of the methods and systems used it can be seen that through all of these run certain rules, inherent to its theory and practice. 


\section{QA at SFX}

The plan

Our first action was to specify the aims and objectives of the QA programme, deciding what it was intended to achieve and for whom. The QA programme at SFX was based on a number of priorities: to keep it simple and manageable; to keep it flexible; to combine quantitative and qualitative measurement; and to achieve a system which would provide us with a management tool, as well as satisfying the funding authority.

We decided that, rather than use any one particular method, we would use the basic rules for other systems to evolve our own, modifying and simplifying the techniques which we had read about to build a system which was specific to our own work and environment. What was needed was a programme that if followed would ensure quality service and facilities, at the same time offering evidence of user satisfaction and cost-effectiveness. The QA programme at SFX, therefore, was to be a continuous cycle of setting standards, rectifying shortfalls and meeting goals. This we hoped to achieve by ensuring that certain tasks were carried out on a regular basis, standardizing and documenting procedures, formalizing meetings so that minutes were always taken and kept, ensuring that certain items appeared in the annual report every year, and by setting standards (staff, stock, service, etc). As a result we hoped to have not just a list of statistics, but also a tool which would aid the day-to-day management of the library and would put us in a strong position to plan for the future, defend current funding and justify future development.

\section{The process}

Aims and objectives. So how did we go about it? By using a similar structure to that which we had read about time and time again, viz; starting from the College Mission Statement we first developed a Mission Statement for our own department; secondly, the aims and objectives of the library which showed, still in fairly general terms, how the Mission Statement would be put into practice; and thirdly, the projects and targets which were precise goals, and which would need to be reviewed and revised on an annual basis to ensure a flexible approach.

Quality characteristics. Our QA programme was just part of a college-wide programme. Although we were free to develop the system as we saw fit, setting out our own targets and measures, we did have to fit in with a standardized list of headings (quality characteristics) which was given to all departments by the college management as a framework from which to build the programme. The categorization of headings with which we were presented bore little resemblance in terms of format to our breakdown of the aims and objectives. There was a strong bias towards the teaching departments inherent in the list and it was not always obvious how to fit our aims to the headings. On a more positive note, this forced us to look at the library as a section of a unified entity and to consider our functions as part of the aims and objectives of the college as a whole. By looking at the library from this new perspective we were able to see the relevance of headings, which at first, had not seemed to have any implications for us. The benefit to the college of an integrated approach is obvious; the standardization of headings throughout all departments means that it is possible to evaluate quality on a college-wide basis as well as in each individual department. Although each heading can be interpreted by departments in a different manner it is still feasible to amalgamate the college response, thus providing an overall picture of QA within the college. 
The other benefit to the system in its early stages was that as college management stated; "By working through some of the procedures from a variety of different angles or departmental perspectives we are likely to get a much better idea of how to refine the system ${ }^{(\mathrm{A}, \mathrm{p} 2) \text { "). }}$

Quality standards and measures. Once the quality characteristics had been checked for relevance, the next task was to devise standards and measures for each characteristic. The following definitions were given by college management as an aid:

"Quality standard - is the procedure adopted and the realistic standard that could be achieved on the relevant characteristic given current levels of resourcing. In some cases it may be regarded as a target.

Quality measure - is the way in which we evaluate how successful we have been in achieving the standard we have set for the quality characteristic ${ }^{(\mathrm{B}, \mathrm{p} 1)}$ '”.

Standard setting was relatively simple in most cases as our aims and objectives were often specific enough to transfer to the relevant heading. The main problem which we encountered was not what standard to set, but how to measure the work against that standard. Standards showing an obvious tendency towards statistical measurement were relatively easy to set; eg:

\begin{tabular}{|c|c|}
\hline Quality characteristic & - $\quad$ Target enrolments \\
\hline Quality standard & $\begin{array}{l}\text { - } 70 \% \text { of students to be registered as users of the library by } \\
\text { the end of the Autumn term }\end{array}$ \\
\hline Quality measure & $\begin{array}{l}\text { - Total number of students divided by number of students } \\
\text { registered as library users. Annual report. }\end{array}$ \\
\hline
\end{tabular}

(The example shows that after the quality measure we noted where documented evidence could be found.)

Qualitative standards were largely measured through a user questionnaire to be carried out in alternate years for students and staff.

\section{The documentation}

Much of our work was based on the idea of documenting all library systems and procedures, and maintaining a strict timetable of when and how to carry out these procedures. Standardization of working methods would reduce the margin of error and work would be carried out within an allotted time-scale. The documents would serve not only as an aid to staff, but would also provide much of the physical evidence of the QA system. Documentation was divided into four main headings:

Departmental handbook; holding information on all library procedures and policies.

Annual report; showing the results of on-going projects, analysis of user questionnaires, and including many of the QA statistics.

Staff training manual; giving a detailed and structured training programme for new members of staff.

Departmental records; providing documentation for all remaining items of QA, eg; minutes of meetings, records of health and safety checks, budget proposals, etc. 


\section{Conclusions and Recommendations}

\section{Achievements}

Increased resources. Since I completed the research project in 1994, we have seen material benefits result from our work. Records of student use of computers within the library were used to justify the installation of six extra terminals at the beginning of the 1993/4 academic year. Similarly, records of CD-ROM use have led to an allowance in the 1994/5 budget for a further CDROM in the library and one for each faculty in the college. Increased use of the library in 1992/ 3 , due to rising student numbers, led to an expansion of the library in the summer of 1993. Although this was not totally resultant from our QA programme, usage figures undoubtedly backed up our request for improved resources.

Documentation. Documentation of all procedures took place in 1993 and has since been revised in response to changes. It has provided a strong base from which to train new members of staff.

User questionnaire. The results of the 1993 student survey gave sound opinions on how library facilities and services could be improved. Many of these points have been acted upon. We have also recently analyzed the 1994 staff survey which has highlighted further areas for development.

Enquiry monitoring. For one week each month we list each enquiry and note whether material was found to meet the need. For the past two years we have maintained an $80 \%$ satisfaction rate, are developing a better picture of student needs and are becoming more responsive to correcting deficiencies in stock.

Opening hours. One of our QA standards stated that the library would be open from half an hour before the college day to one hour after. The extension of the college day has meant that in order to fulfil this standard there are longer periods when only one member of staff is on duty. This is hardly a desirable position, but we felt that we should maintain the set standard despite the problems which it presents.

When I began my research project in 1992 there was a dearth of literature on QA in sixth form libraries, reflecting the fact that until recently QA simply has not been an issue in this sector.

There are similarities between most sixth form colleges in terms of numbers of students, courses run, etc., and as a result the libraries are comparable. It is foreseeable that other sixth form librarians will face many of the problems which SFX librarians faced in the development of a QA programme. It is also likely that sixth form colleges introducing QA will require an integrated approach which endeavours to present all the services and facilities of a college under a single list of headings. In addition, similarities in terms of numbers of library staff make it likely that librarians will be concerned to find a system that does present too great a workload which might limit or affect services currently offered.

What, then, are the lessons to be learned from the SFX project?

- Read the literature, find a method that looks practical, and adapt it to suit your environment. 
- $\quad$ Decide who the programme is for; to satisfy a funding council; to be used as a management tool for the ultimate benefit of library users; or to serve both purposes.

- If a programme is to be 'invented' then follow the basics. Review the organizational and departmental aims and objectives before starting to measure anything, and bear those aims in mind continually as the programme is developed.

- The involvement of all staff, and the support of top management are essential from the outset.

- $\quad$ Expect to spend a great deal of time on QA in the first year of development.

- $\quad$ Keep it simple.

- Remember that while data collection should not affect the day-to-day running of the department, the data collected must be accurate enough to give a true picture.

- Keep a balance between qualitative and quantitative data - both are needed.

- And finally? Remember that it is an on-going programme; that revisions to both the programme and the aims are desirable. Increasing experience of QA will mean that more efficient and effective methods of working and measurement will be found. If the project is to be effective in the long term, there must be flexibility to reflect the changing nature of both the college and the library.

\section{References}

1. Demonstrating library value: a report of a research investigation. C Oldman, in Studies in Library Management, vol 7, Vaughan A (ed), London: Bingley, 1982, pp117-143.

2. Fredenburg, A. Quality assurance: establishing a program for special libraries. Special Libraries, vol 79, no 4, Fall 1988, pp277-284.

In-house documents quoted:

A. The development of a quality assurance system - INSET day - 4 December 1992 - agenda and notes - Curriculum Standards Committee.

B. Quality definitions - Curriculum Standards Committee. 